\title{
Experimental anxiety and the reinforcing effects of ethanol in rats
}

S.L. Blatt and

R.N. Takahashi
Departamento de Farmacologia, Centro de Ciências Biológicas,

Universidade Federal de Santa Catarina, Florianópolis, SC, Brasil

\section{Correspondence \\ R.N. Takahashi \\ Rua Ferreira Lima, 82 \\ 88015-420 Florianópolis, SC \\ Brasil \\ Fax: +55-48-222-4164}

Presented at the 6 th World Congress of Biological Psychiatry, Nice,

France, June 22-27, 1997.

Research supported in part by CN Pq S.L. Blatt was the recipient of a fellowship from CNPq.

Received July 30, 1998

Accepted January 11, 1999

\section{Abstract}

In order to examine the relationship between anxiety and reinforcing effects of alcohol, drug-naive male Wistar rats weighing 250-300 g were classified as "anxious" and "non-anxious" in the elevated plusmaze test. A conditioned place preference test was then used to investigate the reinforcing effects of ethanol $(\mathrm{EtOH})$ on these animals. On 2 alternate days, groups of "anxious", "non-anxious" and "normal" rats received intraperitoneal (ip) injections of $\mathrm{EtOH}(0.5,1.0$ or $1.5 \mathrm{~g} / \mathrm{kg}$ ) immediately before a 15 -min confinement to the white compartment. On the 2 intervening days the same rats received ip injections of saline before confinement to the opposite compartment. On day 5, a 15-min free-choice test was carried out with no injections. Rats classified as "anxious" showed a significant, though not dosedependent preference for all doses of ethanol compared to salinetreated animals. These data demonstrate that rats regarded as "anxious" are more sensitive to the reinforcing effects of EtOH than "nonanxious" and "normal" Wistar rats and emphasize the relevance of the basal levels of anxiety of rats when trying to detect the reinforcing effects of EtOH.

\section{Introduction}

The reinforcing properties of drugs of abuse are seen as the major factor leading to drug-seeking behavior and to a subsequent addictive state. However, probably due to a more complex pharmacodynamic action of ethanol (EtOH) than of other addictive drugs, the demonstration of reinforcing effects of EtOH in animal models has been difficult to achieve $(1,2)$. Thus, in the conditioned place preference (CPP) paradigm, which has been used widely to study the rewarding effects of various drugs of abuse (3-5), studies with ethanol have generated conflicting results $(1,2,6)$. In this context, it is important to
Key words

- Anxiety

- Plus-maze

- Place preference

- Ethanol

- W istar rats mention that an additional and prevalent notion holds that acute anti-anxiety actions of EtOH are important for the reinforcing properties of this drug. Therefore, the tensionreduction hypothesis, though controversial, proposes that there is a high comorbidity for several anxiety disorders and alcohol abuse in clinical and epidemiological studies (7-9).

One of the most widely used animal models of anxiety is the elevated plus-maze which has been pharmacologically and ethologically validated $(10,11)$. Using this procedure, recent studies have shown remarkable straindependent differences in the anxiety response of inbred rats (12) as well as normal Wistar rats (13). Moreover, basic studies on labora- 
tory animals attempting to validate the tension-reduction hypothesis have produced conflicting results. For example, in heterogeneous populations of Wistar rats, high baseline levels of experimental anxiety have been reported to predict high voluntary EtOH self-administration (14), whereas more contradictory results have been reported with rat lines bred for $\mathrm{EtOH}$ preference $(15,16)$. Since little is known about the possible interaction between experimental anxiety and the effects of alcohol, in the present study we investigated the relationship between different levels of anxiety and the reinforcing effects of EtOH in rats. For this purpose, drug-naive Wistar rats were tested in the elevated plus-maze for their initial level of anxiety. Rats were then classified as anxious and non-anxious and subsequently tested in a conditioned place preference paradigm.

\section{Material and Methods}

\section{Animals}

Male Wistar rats weighing 250-300 g from our colony were used. The animals were housed in groups of 6 in plastic cages and maintained in a room with controlled temperature $\left(23 \pm 1^{\circ} \mathrm{C}\right)$ and a 12-h light cycle (lights on 7:00 h) with food and tap water available ad libitum.

\section{Drugs}

Ethanol (Merck) was diluted in $\mathrm{NaCl}$ to $10.0 \%(\mathrm{w} / \mathrm{v})$ concentration. The control solution consisted of an equivalent volume of saline. All drugs were administered intraperitoneally.

\section{Apparatus}

Elevated plus-maze test. The wooden plus-maze consisted of two opposite $50-\mathrm{cm}$ long $\mathrm{x} 10-\mathrm{cm}$ wide open arms and two $50 \mathrm{x}$
$10 \times 40 \mathrm{~cm}$ (length, width and height) enclosed arms. The arms extended from a central $10 \times 10-\mathrm{cm}$ platform. The maze was elevated to a height of $50 \mathrm{~cm}$ above the floor. The enclosed arms were painted black. To determine the exploratory activity of rats, white tapes (about $2 \mathrm{~mm}$ wide) were used to divide the floor of each open arm into three equal sectors.

The procedure of the test was as described previoulsy (13). Briefly, each rat was placed in the center of the maze and time spent in the open and closed arms was recorded over a 5-min test period by an observer sitting at a distance of approximately $1 \mathrm{~m}$ from the apparatus. In addition, the following parameters were recorded: the latency period to the first entry into one of the open arms of the maze and the number of sectors crossed in the open arms. To consider an animal as anxious, the two parameters measured had to correlate. Thus, rats that crossed fewer sectors than 10 and spent a total time in open arms of less than $60 \mathrm{~s}$ were considered to be anxious. The nonanxious group consisted of rats that crossed more than 20 sectors and spent more than $120 \mathrm{~s}$ in the open arms. The cut-off times applied were established using the mean value of time spent in the open arms \pm 3 SEM. One week after selection, anxious, non-anxious and normal rats received control solution or EtOH $(0.5,1.0$ or $1.5 \mathrm{~g} / \mathrm{kg}) 15 \mathrm{~min}$ prior to testing in the conditioned place preference test. A total of 263 rats were used in the plusmaze test for the selection procedure which provided 65 anxious, 68 non-anxious and 130 normal rats.

\section{Conditioned place preference}

Place conditioning and testing was conducted using a $30 \times 30 \times 22 \mathrm{~cm}$ two-chambered acrylic cage. One white end was illuminated with a $40-\mathrm{W}$ white light bulb and had a floor grid and the other end was black and had a smooth white floor. 
A biased place-conditioning procedure was used. The conditioning period of this experiment lasted 4 consecutive days. On days 1 and 3, animals received control solution, were immediately placed in the black end chamber and confined there for $15 \mathrm{~min}$. On days 2 and 4, rats were injected with $\mathrm{EtOH}(0.5,1.0$ or $1.5 \mathrm{~g} / \mathrm{kg})$ and immediately confined to the white chamber for the same 15-min period. The apparatus was cleaned after each conditioning session with a cloth dampened with $10 \%$ ethanol.

During the next day (the fifth day) uninjected rats were given free access to the two sections of the apparatus and the number of seconds each subject spent in each chamber was recorded for $15 \mathrm{~min}$. The location of the animal was defined by the position of the four paws in the compartment.

For this procedure, three main groups of rats were formed and divided into 4 experimental groups, each consisting of at least 10 rats.

\section{Measurement of blood ethanol}

A separate group of rats submitted to the same injection schedule as in the CPP test was used to determine blood EtOH concentration. Fifteen minutes after the last $i p$ injection of $\mathrm{EtOH}(0.5,1.0$ or $1.5 \mathrm{~g} / \mathrm{kg})$ or saline, animals were anesthetized with ether and blood was collected by cardiac puncture. Plasma aliquots were stored at $2-4^{\circ} \mathrm{C}$ for later determination of EtOH levels. The determination of alcohol in the blood was based on the titration reaction technique of Nicloux (17).

\section{Statistical analysis}

The data are reported as means \pm SEM and were analyzed statistically by analysis of variance (ANOVA) followed by the Newman-Keuls post hoc test. Differences were considered to be significant when $\mathrm{P} \leq 0.05$.

\section{Results}

Table 1 summarizes the results of the selection procedure of drug-naive rats in the plus-maze test for their basal level of anxiety. The subsequent division into anxious, non-anxious and normal rats resulted in statistically well-differentiated groups $\left[\mathrm{F}_{2,89}=\right.$ $31.069, \mathrm{P}<0.0001]$. Thus, rats classified as non-anxious exhibited shorter latencies to entry into the open arms, crossed more sectors, and spent more time in the open arms of the maze compared to normal rats. All of these measurements suggest reduced aversiveness in the non-anxious subgroup. The opposite was true for rats assigned to the anxious subgroup.

Figure 1 shows the results of place preference conditioning for anxious, non-anxious and normal rats in the elevated plusmaze. As can be seen, a significant preference for the treatment-paired compartment was observed in anxious rats injected with EtOH $(0.5,1.0$ or $1.5 \mathrm{~g} / \mathrm{kg}, i p)\left[\mathrm{F}_{6,64}=3.52\right.$, $\mathrm{P}<0.045]$. In non-anxious rats, EtOH, $0.5 \mathrm{~g} /$ $\mathrm{kg}$, caused an increase of time spent on the drug-paired side; however, this response did not reach statistical significance (Figure 1). These results indicate the reinforcing properties of EtOH only in anxious rats as measured in the place preference paradigm.

Since no variations were detected in blood EtOH levels among the different groups of rats, the data were pooled for each dose. Blood EtOH concentrations measured in

Table 1 - Selection experiment according to the exploratory activity of naive undrugged Wistar rats in an elevated plus-maze.

Data are reported as the mean $\pm \mathrm{SEM}$. $* \mathrm{P} \leq 0.05$ compared to the normal group (oneway ANOVA and Newman-Keuls test).

\begin{tabular}{lcccc}
\hline & $\begin{array}{c}\text { Latency of first } \\
\text { open-arm entry (s) }\end{array}$ & $\begin{array}{c}\text { Number of crossed } \\
\text { sectors in open arms }\end{array}$ & $\begin{array}{c}\text { Total time spent } \\
\text { in open arms (s) }\end{array}$ & $\begin{array}{c}\text { Number } \\
\text { of rats }\end{array}$ \\
\hline Non-anxious & $6.6 \pm 0.9$ & $25.3 \pm 0.9^{*}$ & $138.4 \pm 7.6^{*}$ & 48 \\
Normal & $9.0 \pm 1.6$ & $15.8 \pm 0.2$ & $93.4 \pm 3.4$ & 44 \\
Anxious & $63.8 \pm 12.4^{*}$ & $6.0 \pm 0.5^{*}$ & $42.1 \pm 3.4^{*}$ & 45
\end{tabular}


Figure 1 - Mean time (s) spent on the test day in the previously drug-paired compartment of the place preference apparatus. Place conditioning sessions were held for 4 days for anxious, non-anxious and normal rats injected ip with saline or ethanol (EtOH) $(0.5,1.0$ or $1.5 \mathrm{~g} /$ $\mathrm{kg})$. Data are reported as the mean \pm SEM. Numbers in parentheses indicate the size of the groups. $* P \leq 0.05$ compared to the control group (NewmanKeuls test).

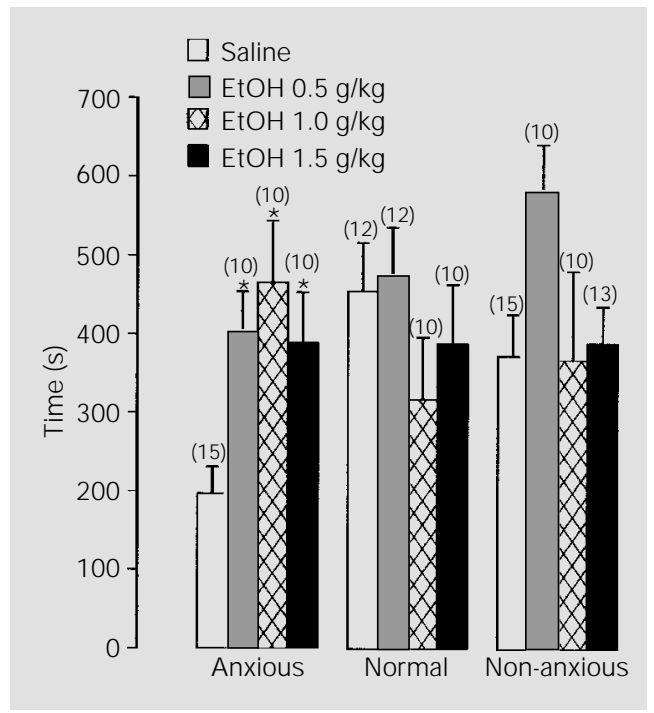

animals 15 min after ip injection of EtOH $(0.5,1.0$ and $1.5 \mathrm{~g} / \mathrm{kg})$ yielded the following means: $7.9,15.9$ and $19.4 \mathrm{mg} / \mathrm{dl}$, respectively.

\section{Discussion}

The wide variation in anxiety levels observed in the plus-maze in an outbred Wistar rat population is consistent with the results of our earlier study (13) and suggest a genetic heterogeneity for the anxiety response.

The most important finding of the present study is that EtOH induces reinforcing effects as measured in the conditioned place preference paradigm only in rats classified as anxious. These results confirm the notion that $\mathrm{EtOH}$ may possess weak reinforcing properties in normal rats. For example, most place-conditioning studies show no effects of low EtOH doses and conditioned place aversions at higher doses $(18,19)$. A few studies have shown EtOH-induced CPP in rats with a history of pre-exposure to $\mathrm{EtOH}$ $(6,20,21)$ or when the drug is combined with food $(22,23)$ or morphine $(20,24)$. Bozarth (1) reported place-preference without any EtOH pre-exposure after 15 drug-compartment pairings, suggesting that a longer conditioning period might be necessary to asso- ciate weak positive reinforcing properties of EtOH with a distinct compartment.

As mentioned previously, the relationship between anxiety and EtOH has been a matter of considerable controversy. The present data showing that anxious rats developed place preference after a short period of conditioning, 4 days, favor the hypothesis that the anxiety state may contribute to the vulnerability to EtOH intake. Thus, in a recent study Spanagel et al. (14) showed a significantly higher intake and preference for $\mathrm{EtOH}$ in rats selected as anxious in the plus-maze test, which led them to suggest that the degree of anxiety may underlie, at last in part, the initial motivation to drink alcohol. These results agree with the study of Stewart et al. (16) which indicated a higher degree of anxiety in EtOH-preferring than non-preferring rats.

In addition, blood EtOH levels measured within the time range of $15 \mathrm{~min}$ for the behavioral test were dose-dependent and seemed to be sufficient to influence the place preference conditioning.

Although not tested in the present investigation, it is important to emphasize that studies in this laboratory using EtOH in a quite similar dosage range $(0.8-1.2 \mathrm{~g} / \mathrm{kg}$, ip $)$ did not find differences in anxiety measurements recorded in the plus-maze test (25). Therefore, it is likely that the results of place preference conditioning were not confounded by the potential anxiolytic effect of EtOH. Also, the locomotor activity of these animals was measured and dissociated from a sedative action of $\mathrm{EtOH}$ at the doses used here in our study (data not shown).

In conclusion, the present data demonstrate a significant place preference for the EtOH-paired compartment by rats previously selected to be anxious. In addition, these results emphasize the relevance of basal level of anxiety of rats in terms of sensitivity to the reinforcing effects of EtOH and may contribute to the understanding of alcohol dependence. 


\section{References}

1. Bozarth MA (1990). Evidence for rewarding effects of ethanol using the conditioned place preference method. Pharmacology, Biochemistry and Behavior, 35: 485-487.

2. Stewart RB, Murphy J M, McBride WJ , Lumeng L \& Li TK (1996). Place conditioning with alcohol in alcohol-preferring and non-preferring rats. Pharmacology, Biochemistry and Behavior, 53: 487-491.

3. Barr GA, Paredes W \& Bridger WA (1985). Place conditioning with morphine and phencyclidine; dose dependent effects. Life Sciences, 36: 363-368.

4. Shippenberg TS \& Heidbreder CH (1995). Sensitization to the conditioned rewarding effects of cocaine: pharmacological and temporal characteristics. J ournal of Pharmacology and Experimental Therapeutics, 273: 808-815.

5. Shoaib M, Stolerman IP \& Kumar R (1994). Nicotine-induced place preferences following prior nicotine exposure in rats. Psychopharmacology, 113: 445-452.

6. Reid LD, Hunter GA, Beaman CM \& Hubbell CL (1985). Toward understanding ethanol's capacity to be reinforcing: a conditioned place preference following injections of ethanol. Pharmacology, Biochemistry and Behavior, 22: 483-487.

7. George DT, Nutt DJ , Dwyer BA \& Linnoila M (1990). Alcoholism and panic disorder: Is the comorbidity more than coincidence? Acta Psychiatrica Scandinavica, 81: 97-107.

8. Kushner MG, Sher KJ \& Beitmen BD (1990). The relation between alcohol problems and anxiety disorders. American J ournal of Psychiatry, 147: 685-695.

9. Schuckit MA \& Hesselbrock V (1994). Alcohol dependence and anxiety disorders: what is the relationship? American J ournal of Psychiatry, 151: 1723-1734.

10. Pellow S, Chopin P, File SE \& Briley M (1985). Validation of open:closed arm entries in an elevated plus-maze as a measure of anxiety in the rat. J ournal of Neuroscience Methods, 14: 149-167.

11. Rodgers TJ , Cao B-J, Dalvi A \& Holmes A (1997). Animal models of anxiety: an ethological perspective. Brazilian J ournal of Medical and Biological Research, 30: 289304.

12. Ramos $A$, Berton $O$, Mormede $P$ \& Chaouloff $F$ (1997). A multiple-test study of anxiety-related behaviours in sex inbred rat strains. Behavioural Brain Research, 85: 57-69.

13. Rogério R \& Takahashi RN (1992). Anxiogenic properties of cocaine in the rat evaluated with the elevated plus-maze. Pharmacology, Biochemistry and Behavior, 43: 631-633.

14. Spanagel $R$, Montkowski A, Allingham $K$, Stöhr T, Shoaib M, Holsboer F \& Landgraf R (1995). Anxiety: a potential predictor of vulnerability to the initiation of ethanol self-administration in rats. Psychopharmacology, 122: 369-373.

15. Moller $C$, Wiklund L, Thorsell A, Hytia P \& Heilig M (1997). Decreased measures of experimental anxiety in rats bred for high alcohol preference. Alcoholism: Clinical and Experimental Research, 21: 656-660.

16. Stewart RB, Gatto GJ , Lumeng L, Li T-K \& Murphy J M (1993). Comparison of alcohol preferring $(\mathrm{P})$ and non-preferring (NP) rats on tests of anxiety and for the anxiolytic effects of ethanol. Alcohol, 10: 1-10.

17. Sica P (1983). Alcoolismo e Portaria do Contran: Uma Resolução Importante. O Laudo, Porto Alegre, 49-55.
18. Asin KE, Wirtshafter $D \& \&$ Tabakoff $B$ (1985). Failure to establish a conditioned place preference with ethanol in rats. Pharmacology, Biochemistry and Behavior, 22: 169-173.

19. Cunningham CL (1979). Flavor and location aversion produced by ethanol. Behavioral and Neural Biology, 27: 362-367.

20. Bienkowski P, Kuca P, Piasecki J \& Kostowski W (1996). Low dose of ethanol induced conditioned place preference in rats after repeated exposures to ethanol or saline injections. Alcohol and Alcoholism, 31: 547-553.

21. Gauvin DV, Briscoe RJ , Baird TJ , Vallet M $\&$ Holloway FA (1997). The paradoxal hedonic valence of acute ethanol withdrawal (hangover) states in rats: place and taste conditioning. Alcohol, 14: 261-268.

22. Stewart RB \& Grupp LA (1985). Some determinants of the motivational properties of ethanol in the rat: Concurrent administration of food or social stimuli. Psychopharmacology, 87: 43-50.

23. Stewart RB \& Grupp LA (1981). An investigation of the interaction between the reinforced properties of food and ethanol using the place preference paradigm. Progress in Neuropsychopharmacology, 5: 609-613.

24. Marglin SH, Mackechine DK, Mattie ME, Hui Y \& Reid LD (1988). Ethanol with small doses of morphine establishes a conditioned place preference. Alcohol, 5: 309-313.

25. Ferreira VMM \& Morato GS (1996). Influence of age and pre-treatment with $\mathrm{D}$ cycloserine on the behavior of ethanoltreated rats tested in the elevated plusmaze apparatus. Addiction Biology, 1: 395-404. 